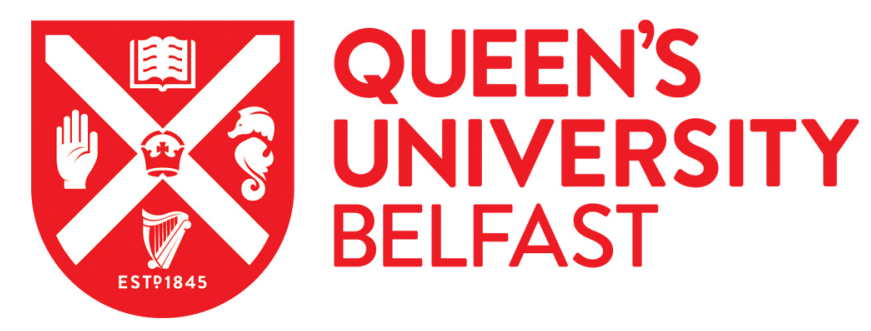

\title{
Veganism: are future pharmacists ready to provide advice?
}

Hanna, L-A., Carabine, F., Hall, M., Craig, R., \& Hanna, A. (2021). Veganism: are future pharmacists ready to provide advice? Currents in Pharmacy Teaching and Learning, 13(5), 512-519.

\author{
Published in: \\ Currents in Pharmacy Teaching and Learning
}

\section{Document Version:}

Peer reviewed version

Queen's University Belfast - Research Portal:

Link to publication record in Queen's University Belfast Research Portal

\section{Publisher rights}

Copyright 2021 Elsevier.

This manuscript is distributed under a Creative Commons Attribution-NonCommercial-NoDerivs License

(https://creativecommons.org/licenses/by-nc-nd/4.0/), which permits distribution and reproduction for non-commercial purposes, provided the author and source are cited.

\section{General rights}

Copyright for the publications made accessible via the Queen's University Belfast Research Portal is retained by the author(s) and / or other copyright owners and it is a condition of accessing these publications that users recognise and abide by the legal requirements associated with these rights.

Take down policy

The Research Portal is Queen's institutional repository that provides access to Queen's research output. Every effort has been made to ensure that content in the Research Portal does not infringe any person's rights, or applicable UK laws. If you discover content in the Research Portal that you believe breaches copyright or violates any law, please contact openaccess@qub.ac.uk. 


\section{Veganism: are future pharmacists ready to provide advice?}

\section{Abstract}

Introduction: In addition to advising about diets, nutritional deficiencies and supplements, pharmacists should be confident discussing medicine-related issues that may arise from people adopting veganism, including checking about animal-derived pharmaceutical product excipients, formulation processes and determining whether vegan-friendly alternatives exist. Thus, this study aimed to investigate pharmacy students' knowledge and views about veganism.

Methods: Given veganism's increasing popularity and relevance to pharmacy practice, students enrolled in their last year of the undergraduate Master of Pharmacy degree program at Queen's University Belfast participated in this voluntary study. The questionnaire was given out at an obligatory workshop (only non-identifiable data were requested). Students were scored on veganism knowledge (22 statements; true/false answers) with other analysis about views being largely descriptive in nature. Results: Ninety-two out of 101 (91.1\%) completed the questionnaire. Only one reporting being vegan. Mean knowledge score (possible range of 0-22) was 16.59 ( \pm 2.43$)$; Only $37.0 \%$ (34/92) reported feeling confident discussing veganism with patients or other healthcare professionals and $40.2 \%(37 / 92)$ deemed they could establish whether a medical product is vegan-friendly. A minority $[4.3 \%(4 / 92)]$ considered they had received adequate training on veganism. A greater proportion of males than females considered that vegans are too forceful with their beliefs $[74.2 \%(23 / 31)$ versus $51.7 \%(31 / 60)]$. Conclusions: This study presents the first description of pharmacy students' knowledge and opinions on veganism (from a single institution only). The reported gap in educational provision and lack of confidence needs to be investigated and addressed to enhance patient-centered care.

Keywords: pharmacist; questionnaire; undergraduate; veganism.

Conflict of interest: There are none to report.

Disclosures: This study did not receive any funding. The research was conducted in line with the Declaration of Helsinki criteria, with Queen's University Belfast Faculty of Medicine, Health and Life Sciences Research Ethics Committee giving their approval on 7th November 2019 (Ref. MHLS 19_13). The paper is not published in (or being considered by) another journal. All authors have contributed significantly to all stages of the study and this manuscript. Author Contributions: L.H. and F.C. conceptualization; L.H., R.C. and M.H. methodology; A.H. software; L.H. and A.H. validation; A.H. and F.C. formal analysis; F.C. investigation; F.C. resources; F.C. data curation; L.H. and A.H. writing- 
original draft preparation; L.H. and R.C. writing-review and editing; L.H. and F.C. visualization; L.H supervision; L.H and M.H project administration; N/A funding acquisition.

\section{Introduction}

The Vegan Society [a United Kingdom (UK) based educational charity and the oldest vegan society in the world] defines veganism as "a philosophy and way of living which seeks to exclude, as far as possible and practicable, all forms of exploitation of, and cruelty to, animals for food, clothing or any other purpose; and by extension, promotes the development and use of animal-free alternatives for the benefit of animals, humans and the environment." 1 Thus, being vegan impacts a person's lifestyle including their diet, choice of clothes, cosmetics, forms of entertainment, medicines, and other aspects of daily life including money (as tallow in polymer bank notes is made from animal fat). Interest in veganism has been increasing in recent years across many countries, as illustrated in Figure $1 .{ }^{2}$

Most of the published peer reviewed research about veganism and the vegan (or plant-based) diet relates to establishing whether there are risks and/or benefits to health and patient outcomes. For example, in terms of risks of a vegan diet, it may be associated with megaloblastic anemia and psychosis, ${ }^{3}$ higher fracture rates, ${ }^{4}$ orthorexia nervosa ${ }^{5}$ and hypothyroidism. ${ }^{6}$ Moreover, Dobersek and colleagues ${ }^{7}$ concluded that various mental health conditions (including depression and anxiety) were more likely in those who avoided eating meat. There may be benefits of a vegan diet, although there is a paucity of robust, long-term data. A systematic review (eighty-six studies) found that vegetarians and vegans had significantly reduced levels of total cholesterol, glucose and body mass index in comparison to omnivores ${ }^{8}$ and that a vegan diet was associated with a reduced risk incidence from total cancer. ${ }^{8}$ Abbasnezhad et al $^{9}$ concluded (based on a review and meta-analysis of 24 studies involving patients with type 2 diabetes) that a vegan diet was significantly better at reducing blood pressure compared to a control diet while Trepanowski and Varady ${ }^{10}$ found that vegan diets seemed to improve glycemic control in patients with type 2 diabetes to a greater extent than the American Diabetes Association diet.

In other research, Rosenfeld and Burrow ${ }^{11}$ outlined the development and validation of a "Dietarian Identity Questionnaire", several studies have investigated why people follow a vegan $\operatorname{diet}^{12-15}$ and Markowski and Roxburgh ${ }^{16}$ examined stigmatization in the context of veganism. Corrin and Papadopoulos ${ }^{17}$ deemed the Health Belief Model may be useful to inform health promotion activities (about vegetarian or plant-based diets). 
In terms of research involving healthcare professionals and students, a questionnaire-based study has been conducted among physicians to examine if there is any association between dietary choice and empathy levels. ${ }^{18}$ Krause and Williams ${ }^{19}$ conducted a questionnaire-based study in the United States of America to determine medical student and faculty understanding and adoption of plant-based nutrition. They found that understanding about plant-based nutrition appeared reasonable. ${ }^{19}$ Additionally, in terms of a plant-based diet, around a third would suggest it to patients and over a quarter would potentially try it themselves. ${ }^{19}$ However, no work has been published which ascertains future pharmacists' (or licensed pharmacists) knowledge and views on the subject area.

The rise in internet search queries depicted in Figure 1 clearly demonstrates that people are seeking information on veganism (and provides pharmacists with an opportunity to demonstrate that they can be a fundamental source of reliable health information). Furthermore, a recent publication about pharmaceutical excipients and general considerations for vegan patients ${ }^{20}$ prepared by a team of specialist pharmacists working in the UK National Health Service (NHS) Medicines Information sector, reiterates that questions are arising about this subject area in pharmacy practice. Pharmacists and future pharmacists have a role in advising people about various diets, outlining the risks and complications of nutritional deficiencies, and providing evidence-based information on nutritional supplements. However, unlike other diets, veganism has implications for pharmacists beyond the provision of nutritional advice. Pharmacists, as experts in medicines, should be confident discussing medicine-related issues that may arise from people adopting veganism, including checking about animal-derived pharmaceutical product excipients, formulation processes and determining whether suitable alternatives exist. Ethically, pharmacists should strive to ensure that medicines are selected and used appropriately, while also respecting patient autonomy and personal beliefs..$^{21,22}$

The objectives of this study were to: ascertain pharmacy students' knowledge of veganism and the vegan diet; determine pharmacy students' opinions towards veganism and the vegan diet (including whether students considered that they had received adequate training in the area during the university degree program); and investigate whether various parameters (gender and vegan status) affected responses. 


\section{Methods}

The selected group of potential participants were Queen's University Belfast (QUB) 2019-2020 final year Master of Pharmacy (MPharm) students $(n=101)$. This year group are soon to graduate and enter the workplace, where they may encounter vegan patients asking for guidance about their medicines or dietary advice. Of all years, final year students should have had the greatest insight into the subject area (or been able to apply knowledge to the greatest extent, in addition to their own societal knowledge about it), having learned about nutrition, pharmaceutical technology, evidence-based healthcare, ethical decision making, and equality, diversity and cultural competency. However, it should be noted that students are not taught directly about veganism on the MPharm degree program as a key subject area.

The questionnaire (outlined below) was given out in an obligatory workshop (which had nothing to do with the questionnaire topic). At the request of the ethics committee, an email invitation was sent to all eligible students several days before questionnaire distribution (data collection) with a participant information sheet attached. The participant information sheet was a standard template used for research studies to outline information about the study including: the purpose, that participation was voluntary, that no identifiable information was being sought, when participants could withdraw (if desired), how consent would be obtained, and data management.

Questionnaire content, particularly for Section A about knowledge of veganism, was informed by peer reviewed systematic reviews about potential health risks and benefits ${ }^{3-10}$, information from the UK NHS about excipients ${ }^{20}$ and the vegan diet, ${ }^{23}$ and guidance from the Vegan Society website. ${ }^{1}$ The questionnaire is available on request from the corresponding author and content included for presentation of the results. Section A related to establishing knowledge and understanding of veganism (all verbatim statements from Section A, in the exact order they were presented in the questionnaire, are provided in Table 1). Section B focused on gaining opinions on veganism, including about training provision provided at QUB School of Pharmacy (all verbatim statements from Section B, in the exact order they were presented in the questionnaire, are provided in Table 2). Section C collected nonidentifiable information about gender and whether the student was currently vegan or not (or would consider becoming vegan in the future). Age (or age range) and ethnicity were not sought as they could potentially identify individual students. There was space in Section C for participants to record any further comments about veganism. The questionnaire contained mostly closed-question style questions 
(as can be seen in Tables 1 and 2) and thus should have been straightforward to complete, in an effort to encourage participation. ${ }^{24}$ Questions were mainly rating or dichotomous (true/false) in nature (as can be seen in Tables 1 and 2). The questionnaire had a cover sheet which summarized the participant information sheet (outlined earlier; including that participation was voluntary and that no identifiable information was being sought) and had a section where students gave their consent to participate. The questionnaire and cover sheet were piloted on ten postgraduate students and postdoctoral staff in QUB School of Pharmacy, with minor changes made based on their feedback, such as clarifying 'vegetarian' was 'lacto-ovo vegetarian' diet (with a footnote explanation of this term).

Following data collection, data were assigned numerical values and recorded in Excel ${ }^{\circledR}$ version Office 365 (Microsoft Corporation, Redmond, WA, USA). Data analysis mainly involved descriptive statistics, such as frequencies and percentages. Section A tested knowledge of veganism (using true/false statements; correct response scored 1 ; incorrect/no response 0 ). For statistical analysis, $R$ version 4.0.0 (R Foundation For Statistical Computing, Vienna, Austria) was used. We anticipated a ttest would be conducted on the data to establish if significant differences $(p<0.05)$ in mean scores were evident for the comparator groups (vegan status and gender) but t-test conditions were not met. The other quantitative data related to opinions (Section B) and Mann Whitney U-Test was to be used for the comparator group analysis. As all test assumptions were not met and the comparator groups were very different in size, only descriptive statistics have been reported. Thematic analysis ${ }^{25}$ was employed for the open response qualitative data (Section C).

Approval to conduct the research was given by Queen's University Belfast Faculty of Medicine, Health and Life Sciences Research Ethics Committee on 7th November 2019 (Ref. MHLS 19_13).

\section{Results}

\section{Level of Participation}

Of the eligible 101 students, 92 participated in this voluntary study giving a response rate of $91.1 \%$. Of the 92 participants (respondents), 7 left one or more questions unanswered in their questionnaire and therefore both percentages and frequencies are provided throughout this section.

\section{Participant Demographics (Section C)}

Gender: $31(33.7 \%)$ male, $60(65.2 \%)$ female and $1(1.1 \%)$ preferred not to disclose this information. For information only (but not gathered as part of the study due to the potential to identifying 
individuals), all except one or two students in the cohort were 21 or 22 years of age, having enrolled immediately after secondary education.

Vegan status: $1(1.1 \%)$ reported being vegan and 91 (98.9\%) reported not being vegan. Of the 91 who reported not being vegan, $16(17.6 \%)$ stated they would consider becoming vegan in the future whereas $75(82.4 \%)$ stated they would not. To enable comparison by vegan status, the 1 respondent who reported being vegan and the 16 who said they would consider it in the future were combined to form the 'yes or maybe' group $(n=17)$. This group was compared with a 'no/never' group $(n=75)$. These two groups, 'yes or maybe' (17 respondents) and 'no/never' ( 75 respondents), are referred to throughout the results.

\section{Open Question (Section C)}

Respondents were asked for reasons about being (or not being) vegan; the main themes (reasons) are provided in Figure 2.

\section{Knowledge About Veganism (Section A)}

Table 1 outlines the 22 verbatim statements used to test knowledge and the corresponding correct answers. The minimum score was 10 out of $22(45.5 \%)$ and the maximum was 22 out of $22(100.0 \%)$. The mean score was $16.59 \pm 2.43(75.4 \%)$ and the median was $17(77.3 \%)$. The lowest scoring questions related to the Vegan Society's stance on medicines and vaccines (Table 1, statements $\mathrm{j}$ and k). The mean and medians for all sub-groups were: male students $16.33 \pm 2.81$, median 17 ; female students $16.78 \pm 2.20$, median 17 , 'no/never' vegan $16.58 \pm 2.29$, median 17 and 'yes or maybe' vegan $16.65 \pm 3.00$, median 17 .

\section{Opinions About Veganism, Including Training (Section B)}

The first question in this section sought opinions on veganism, while the second investigated students' confidence and training provision. Table 2 provides the verbatim statements from the questionnaire, responses, and interpolated median scores.

The highest interpolated medians were for the statements 'Following a vegan diet requires planning and discipline' (4.52) and 'Knowing about veganism is important for my future role as a practicing pharmacist' (3.94). Two of the lowest interpolated medians were for 'I have received adequate training on veganism on the MPharm degree program' (1.84) and 'I would feel confident discussing veganism with patients or other healthcare professionals' (2.47). 
A higher proportion of males than females considered that vegans are too forceful with their beliefs [23/31 $(74.2 \%)$ versus $31 / 60(51.7 \%)]$. A lower proportion of males than females thought that a vegan diet is more expensive than a vegetarian diet [13/31 (41.9\%) versus $43 / 60(71.7 \%)]$ or an omnivore diet $[14 / 31(45.2 \%)$ versus $44 / 60(73.3 \%)]$.

In terms of vegan status, a greater proportion of the 'no/never' group than the 'yes or maybe' group considered veganism to be a trend or fad, not sustainable for individuals on a long-term basis $[25 / 75$ $(33.3 \%)$ versus $3 / 17(17.6 \%)$ ]. Conversely, a greater proportion of the 'yes or maybe' group (than the 'no/never' group) deemed a vegan diet to be better for the environment than one containing meat [14/17 $(82.4 \%)$ versus $36 / 74(48.6 \%)]$, thought that people should cut back on meat consumption to reduce climate change [14/17 (82.4\%) versus $37 / 75(49.3 \%)]$ and felt confident discussing veganism with patients or other healthcare professionals [10/17 (58.8\%) versus 24/75 (32.0\%)].

\section{Discussion}

The number of self-reported vegans was small [1 of 92 respondents $(1.09 \%)]$ but similar to a UK population estimate $(1.16 \%) .{ }^{1}$ Since younger adults typically make up a greater proportion of the vegan population than older adults, it is lower than expected, although the Northern Ireland economy is highly reliant on meat and dairy farming.

The respondents' knowledge about veganism was reasonable in the authors' opinions (given the mean score was over $75 \%$ ) although there is no absolute standard for comparisons. Students who were vegan or would consider becoming vegan had similar knowledge scores to the no/never group. Unfortunately, the respondents' lowest scoring questions are ones that patients may ask about in practice (taking prescribed medicines and getting routine vaccinations, despite their link to animals). It is difficult to avoid medicines which are needed for the management of clinical conditions. However, if vegans knew that The Vegan Society recognizes this and recommends conventional prescribed medicines are taken and routine immunizations given (where no alternative exists, despite being tested or linked to animals), ${ }^{1}$ it would potentially provide some reassurance on this ethical issue. While most respondents knew that vegans avoid gelatin, fewer knew that they avoid lactose, which could cause problems in practice when determining whether a pharmaceutical product is 'vegan-friendly' from its excipients. Knowing about the risks (such as Vitamin $B_{12}$ deficiency) ${ }^{26,27}$ and benefits of a vegan diet also needs to be improved as patients may ask for information about this or nutritional supplements. 
Krause and Williams ${ }^{19}$ reported similar when they asked medical students in the USA about plant-based nutrition (there was a lack of knowledge about $\mathrm{B}_{12}$ with only $58 \%$ correctly agreeing that it should be monitored in those on a plant-based diet). This current study exposed a more general absence of knowledge around which foods are a good source of particular vitamins (again, this could impact on patient counselling). Some students thought that being vegan increases your risk of Vitamin $\mathrm{K}$ deficiency, yet it is typically found in green leafy vegetables. ${ }^{28}$

While most considered that knowing about veganism is important for their future role, only a minority of student pharmacists considered they had received adequate training about it from QUB School of Pharmacy. Indeed, only around one in three felt confident discussing veganism with patients or other healthcare professionals and one in four considered they could establish whether a medical product is vegan-friendly. Vegans, or those who would consider becoming vegan, appeared to be confident about these aspects than the others. This reported gap in educational provision and lack of confidence needs to be addressed by QUB School of Pharmacy. Implications of pharmacists having a lack of knowledge have been discussed above and it will be important to ensure that any training is grounded in scientific evidence, particularly when outlining benefits of veganism and nutritional supplements (in tandem with a wider discussion around the ethical, political and cultural implications of veganism)

The authors acknowledge that while they place great importance on educating QUB pharmacy students about recommending medicines in the context of contra-indications, allergies and intolerances, less emphasis has been placed on the impact of religions and personal beliefs (including veganism) on medicine selection and patient centered-care. Therefore, following reflection about their own provision, they have provided suggestions as to where educators could integrate veganism teaching into pharmacy degree programs (Table 3). Examples of resources to support this teaching include: general considerations for vegan patients about excipients, ${ }^{20}$ implications of religious and cultural beliefs on selection of medicines, ${ }^{29}$ ethical and practical considerations in prescribing animal-derived medication, ${ }^{30}$ databases which provide product ingredients (although it may not be obvious which excipients are animal-derived and thus the manufacturer may need to be contacted directly), health publications databases and government-endorsed organizations (including dietetic associations) information about nutrition and diet. Optional self-directed reading for students (given existing time 
constraints within pharmacy degree programs) could include: vegan and animal ethics societies (websites), "Critical Perspectives on Veganism", ${ }^{31}$ and the "Oxford Handbook of Food Ethics." ${ }^{2}$

Unsurprisingly, vegans, or those who would consider becoming vegan in the future, held more positive views than the others, particularly about the environmental and health benefits of veganism. Reasons for adopting veganism align with those reported in the literature. ${ }^{13-16,33}$ Additionally, the "EATLancet Commission" took a favorable stance for a predominantly plant-based diet given its beneficial effects for the planet. $^{34}$ Evidence-based guidance that integrates health benefits and risks, sustainability, and ethical considerations of veganism could be produced by pharmacy professional organizations, in addition to having other information about pharmaceutical excipients.

\section{Conclusions}

This study presents the first description of pharmacy students' knowledge and opinions about veganism with implications centering on educational and professional organizations providing training and guidance. This work should inspire other teachers to evaluate where and how students learn about veganism given it is increasing in popularity and has relevance to pharmacy practice. The authors would encourage other educators interested in replicating this study to ask students if they knew someone who was vegan (as well as establishing about individual status). In terms of the authors' personal beliefs, four of the five authors are not vegan and one (pharmacy graduate) is considering adopting this practice. All authors know or work with others who are vegan. Three authors are registered pharmacists and pharmacy lecturers, one is a pharmacy graduate, and one is a lecturer in finance. All authors consider they have responsibilities towards protecting the environment and adopting a healthy lifestyle. All place importance in science, evidence and conventional medicines, but respect autonomy and individual choice. The high response rate $(>90 \%)$ reduces the likelihood of non-response bias but subgroups used as comparators (gender and vegan status) were unequal, and/or small, therefore these particular findings should be interpreted with caution. Additionally, this study was conducted with final year students at a single site only. Future research could focus further on the ethical dimension of veganism, other healthcare students' (or professionals') knowledge and views of veganism, and the impact of veganism in professional practice. 


\section{Table and figure information}

Table 1 - see separate file

Table 2 - see separate file

Table 3 - see separate file

Figure 1 - see separate file

Figure 2 - see separate file. [NB: Figure 2 has also been provided as an image within the one spreadsheet file - you will see two tabs at the bottom of the file, one is for the original figure and one is for the image of the figure. This is only in case there are issues copying the original figure whilst also retaining the grey bars within it)]

Figure 1 title:

Figure 1. Google Trends data from January 2004 to January 2020 showing an increasing interest in veganism (scores for each series are measured relative to a value of 100 coinciding with peak interest)

Figure 2 title:

Figure 2. Reasons for being (or not) vegan, with illustrative quotations 


\section{References}

1. The Vegan Society. 1944-2020. Accessed 24 October 2020. https://www.vegansociety.com

2. Google Trends. April 2020. Accessed 24 October 2020. https://trends.google.com

3. Bachmeyer C, Bourguiba R, Gkalea V, Papageorgiou L. Vegan diet as a neglected cause of severe megaloblastic anemia and psychosis. Am J Med. 2019;132(12):e850-e851. doi: 10.1016/j.amjmed.2019.06.025

4. Iguacel I, Miguel-Berges ML, Gómez-Bruton A, Moreno LA, Julián C. Veganism, vegetarianism, bone mineral density, and fracture risk: a systematic review and meta-analysis. Nutr Rev. 2019;77(1):1-18. doi: 10.1093/nutrit/nuy045

5. Dell'Osso L, Abelli M, Carpita B, et al. Orthorexia nervosa in a sample of Italian university population. Riv Psichiatr. 2016;51(5):190-196. doi: 10.1708/2476.25888

6. Yeliosof O, Silverman LA. Veganism as a cause of iodine deficient hypothyroidism. J Pediatr Endocrinol Metab. 2018;31(1):91-94. doi: 10.1515/jpem-2017-0082

7. Dobersek U, Wy G, Adkins J, et al. Meat and mental health: a systematic review of meat abstention and depression, anxiety, and related phenomena. Crit Rev Food Sci Nutr. Published online 20 April 2020. doi: 10.1080/10408398.2020.1741505

8. Dinu M, Abbate R, Gensini GF, Casini A, Sofi F. Vegetarian, vegan diets and multiple health outcomes: A systematic review with meta-analysis of observational studies. Crit Rev Food Sci Nutr. 2017;57(17):3640-3649. doi: 10.1080/10408398.2016.1138447

9. Abbasnezhad A, Falahi E, Gonzalez MJ, et al. Effect of different dietary approaches compared with a regular diet on systolic and diastolic blood pressure in patients with type 2 diabetes: A 
systematic review and meta-analysis. Diabetes Res Clin Pract. Published online 4 April 2020. doi: 10.1016/j.diabres.2020.108108

10. Trepanowski JF, Varady KA. Veganism is a viable alternative to conventional diet therapy for improving blood lipids and glycemic control. Crit Rev Food Sci Nutr. 2015;55(14):2004-2013. doi: $10.1080 / 10408398.2012 .736093$

11. Rosenfeld DL, Burrow AL. Development and validation of the dietarian identity questionnaire: assessing self-perceptions of animal-product consumption. Appetite. 2018;127(2018):182-194. doi: 10.1016/j.appet.2018.05.003

12. Radnitz C, Beezhold B, DiMatteo J. Investigation of lifestyle choices of individuals following a vegan diet for health and ethical reasons. Appetite. 2015;90(2015):31-36. doi: 10.1016/j.appet.2015.02.026

13. Mathieu S, Dorard G. Vegetarianism and veganism lifestyle: motivation and psychological dimensions associated with selective diet. Presse Med. 2016;45(9):726-733. doi: 10.1016/j.lpm.2016.06.031

14. Miki AJ, Livingston KA, Karlsen MC, Folta SC, McKeown NM. Using evidence mapping to examine motivations for following plant-based diets. Curr Dev Nutr. 2020;4(3):nzaa013. doi: $10.1093 /$ cdn/nzaa013

15. Phua J, Jin SV, Kim J. The roles of celebrity endorsers' and consumers' vegan identity in marketing communication about veganism. J Mark Commun. Published online 25 March 2019. doi: $10.1080 / 13527266.2019 .1590854$

16. Markowski KL, Roxburgh S. "If I became a vegan, my family and friends would hate me:" Anticipating vegan stigma as a barrier to plant-based diets. Appetite. 2019;135(2019):1-9. doi: 
10.1016/j.appet.2018.12.040

17. Corrin T, Papadopoulos A. Understanding the attitudes and perceptions of vegetarian and plant-based diets to shape future health promotion programs. Appetite. 2017;109(2017):40-47. doi: 10.1016/j.appet.2016.11.018

18. Kessler CS, Michalsen A, Holler S, Murthy VS, Cramer H. How empathic are vegan medical professionals compared to others? Leads from a paper-pencil-survey. J Clin Nutr. 2018;72(5):780-784. doi: 10.1038/s41430-017-0007-8

19. Krause AJ, Williams KA. Understanding and adopting plant-based nutrition: a survey of medical providers. Am J Lifestyle Med. 2017;13(3):312-318. doi: 10.1177/1559827617703592

20. National Health Service (NHS) UK Medicines Information. Excipients: what are the general considerations for vegan patients? June 2019. Accessed 24 October 2020. https://www.sps.nhs.uk/wp-content/uploads/2019/07/QA-Vegan-excipients-2019-Final.docx

21. Pharmaceutical Society of Northern Ireland. The code: professional standards of conduct, ethics and performance for pharmacists in Northern Ireland. March 2016. Accessed 24 October 2020. http://www.psni.org.uk/about/code-of-ethics-and-standards

22. American Pharmacists Association (APhA). Code of ethics for pharmacists. October 1994. Accessed 24 October 2020. https://www.pharmacist.com/code-ethics

23. National Health Service (NHS). The vegan diet. August 2018. Accessed 24 October 2020. https://www.nhs.uk/live-well/eat-well/the-vegan-diet/ 
24. Dillman DA, Smyth JD, Christian LM. Internet, phone, mail and mixed-mode surveys: the tailored design method. 4th ed. John Wiley \& Sons Inc: 2014.

25. Nowell LS, Norris JM, White DE, Moules NJ. Thematic analysis: striving to meet the trustworthiness criteria. Int J Qual Methods. 2017;16:1-13. doi: 10.1177/1609406917733847

26. The National Institute for Health and Care Excellence (NICE). Anaemia- $B_{12}$ and folate $\begin{array}{lllll}\text { deficiency. } & \text { April } & 2018 . & \text { Accessed } & 24\end{array}$ https://cks.nice.org.uk/anaemia-b12-and-folate-deficiency

27. Selinger $E$, Kühn T, Procházková $M$, Anděl $M$, Gojda J. Vitamin $B_{12}$ deficiency is prevalent among Czech vegans who do not use vitamin $B_{12}$ supplements. Nutrients. 2019;11(12):3019

28. The National Health Service (NHS). Vitamin K. March 2017. Accessed 24 October 2020. https://www.nhs.uk/conditions/vitamins-and-minerals/vitamin-k

29. Anon. Implications of religious and cultural beliefs on selection of medicines. Drug Ther Bull. 2016;54(4):45-48. doi: 10.1136/dtb.2016.4.0396

30. Corfield L, Granne I. Ethical and practical considerations in prescribing animal-derived medication. Postgrad Med J. 2012 Sep;88(1043):497-8. doi: 10.1136/postgradmedj-2012131053

31. Castricano J, Simonsen RR, eds. Critical perspectives on veganism. Springer: 2016.

32. Barnhill A, Doggett T, Budolfson M, eds. The Oxford handbook of food ethics. Oxford University Press: 2018. 
33. Faber I, Castellanos-Feijoó NA, Van de Sompel L, Davydova A, Perez-Cueto FJA. Attitudes and knowledge towards plant-based diets of young adults across four European countries. Exploratory survey. Appetite. 2020;145(2020):104498. doi: 10.1016/j.appet.2019.104498

34. Willett W, Rockström J, Loken B, et al. Food in the anthropocene: the EAT-Lancet commission on healthy diets from sustainable food systems. Lancet. 2019;393(10170):447-492. doi: 10.1016/S0140-6736(18)31788-4 